\title{
NEGATIVE EFFECTS OF VERTEBRATE HERBIVORES ON INVERTEBRATES IN A COASTAL DUNE COMMUNITY
}

\author{
Mikaela Huntzinger, ${ }^{1}$ Richard Karban, ${ }^{2}$ and J. Hall Cushman ${ }^{3}$ \\ ${ }^{1}$ Department of Plant Sciences, University of California, Davis, California 95616 USA \\ ${ }^{2}$ Department of Entomology, University of California, Davis, California 95616 USA \\ ${ }^{3}$ Department of Biology, Sonoma State University, Rohnert Park, California 94928 USA
}

\begin{abstract}
Although competition has been a major focus in ecology for the past century, most empirical and theoretical studies in this area have emphasized interactions between closely related species. However, there is growing evidence that negative interactions among distantly related taxa also occur and may be far more important than previously thought. In this study, we took advantage of an 11-year-old replicated vertebrate-exclosure experiment in a coastal dune community in northern California, USA, to examine the effects of the two most common vertebrate herbivores (jackrabbits and black-tailed deer) on the abundance of the three most visible invertebrate herbivores (two snail, a moth, and a grasshopper species). Our results indicate that four of the six possible pairwise interactions were significantly negative for the invertebrates. Jackrabbits reduced the abundances of snails by $44-75 \%$, tiger moth caterpillars by $36 \%$, and grasshoppers by $62 \%$. Deer reduced the abundances of snails by $32 \%$, increased the abundances of caterpillars by $31 \%$, and had no measurable effect on grasshopper abundance. Our data also revealed that jackrabbits significantly decreased the volume of forbs and common shrubs and the flowering by grasses in our study plots. We were unable to detect an effect of deer on these measures of vegetation. These results suggest that by changing vegetation, jackrabbits may reduce invertebrate populations that are limited by food, protective structures, or microclimate provided by plants. Of these three mechanisms, only shade was strongly supported as limiting snail numbers in smaller-scale manipulations. In most systems, as in this one, the number of pairs of distantly related herbivores far exceeds the number of pairs of congeners. Since interactions among distantly related herbivores may be common in many cases, these interactions are likely to be important and should receive far more attention from ecologists.
\end{abstract}

Key words: amensalism; black-tailed deer; black-tailed jackrabbits; coastal dune community; competition; ecosystem engineering; Helix aspersa; Helminthoglypta arrosa; indirect interactions; interactions between distantly related species; northern California, USA; wooly bear caterpillar.

\section{INTRODUCTION}

Interspecific competition is widely recognized as a dominant force structuring ecological communities. Not surprisingly, the vast majority of competition studies to date have focused on competitive interactions occurring between pairs or groups of closely related species (Connell 1983, Schoener 1983, Gurevitch et al. 1992). This bias has its roots in the long-held view, espoused by Darwin (1859), that closely related organisms have similar morphologies and behaviors, require similar kinds of resources, and are most likely to compete with each other. For example, in The Origin of Species, Darwin (1859: chapter 3) asserted that, "As the species of the same genus have usually, though by no means invariably, some similarity in habits and constitution and always in structure, the struggle will generally be more severe between species of the same genus, when

Manuscript received 21 May 2007; accepted 29 October 2007. Corresponding Editor: B. J. Danielson. they come into competition with each other, than between species of distinct genera."

In real communities, there are many more pairs of distantly related species that could potentially interact than there are pairs of closely related ones. However, interactions between distantly related species have been much less intensively studied than those between congeners (Diamond 1987). This taxonomic bias is widespread although it has been less true for studies of marine intertidal communities where space-occupying organisms from different phyla vie for space (Schoener 1983). Recently, interspecific competition among distantly related organisms within a single phylum has increasingly been identified (e.g., Denno et al. 1995, Ohgushi 2005). Furthermore, in several cases where interactions between organisms from different phyla have been examined, competition has been found (e.g., Morin et al. 1988, Mokany and Shine 2003, Ohgushi 2005). For example, in North American deserts, rodents compete with ants for seeds and suppress ant numbers (Brown and Davidson 1977, Galindo 1986). Ibex 
compete with leaf beetles for flowers and fruits of a cruciferous woody shrub (Gomez and Gonzales-Megias 2002). Similarly, elk and deer depress several leaffeeding insects that rely on host plants shared with these mammalian herbivores (Bailey and Whitham 2002, 2003, Shimazaki and Miyashita 2002). Large ungulates depress the abundance of lizards (Pringle et al. 2007), snakes (McCauley et al. 2006), beetles (Pringle et al. 2007), and grasshoppers (M. Huntzinger and D. Augustine, unpublished data) in an East African savanna by a variety of direct and indirect mechanisms. In most cases, the larger herbivore has been found to depress the smaller since measuring preference and performance of smaller organisms is easier. However, exceptions occur; for example, beetle feeding depressed the preference of deer for sumac bushes (Strauss 1991). In some cases the reverse was true; mammalian herbivores facilitated later feeding by invertebrates (Danell and Huss-Danell 1985, Olofsson and Strengbom 2000; see other references in Karban and Baldwin [1997]). Despite these suggestive results, few studies have asked how common negative interactions among distantly related organisms within a single community are. Examining the interactions of non-congener herbivores will give us a clearer understanding of the true significance of negative interactions in structuring communities.

Distantly related herbivores may interact with each other via a variety of mechanisms. Species may engage in consumptive competition when they both use the same resources, or interference competition when they occupy similar space and can preempt that space or grow over each other. Herbivores commonly interact through less conventionally recognized means as well. For example, herbivores may share a predator, so that increases in one herbivore species enable the predator to increase and enhance predation risk for the second herbivore (Holt and Lawton 1994). One herbivore species can cause changes in the quality of its host plant that result in important consequences for a second herbivore species that uses the same host. Changes to the host plants may be chemical, structural, or involve alterations in climatic regimes experienced by the organisms (Jones et al. 1997, Karban and Baldwin 1997, Ohgushi 2005). Indirect effects are generally as common, as strong, and as fast to become evident as direct effects (Abrams et al. 1995, Menge 1997).

Here, we explore the importance of interactions among distantly related vertebrate and invertebrate herbivores within a coastal dune community in northern California, USA. Rather than selecting herbivores that we suspected were competing as previous researchers have done, we examined the six most abundant and apparent herbivores in our system. Therefore, inclusion in our study was unbiased with respect to our a priori expectations. Our experiment should provide information about the likelihood of negative interactions between distantly related organisms in a model community. Specifically, we asked whether the abundances of four invertebrate herbivore species - two snails, a moth, and a grasshopper-increased when jackrabbits and black-tailed deer were experimentally excluded for 11 years. We then focused on possible trophic and nontrophic mechanisms that could have reduced the abundance of snails in plots with mammalian herbivores. We examined the effects of predation, and availability of food, structure, and shade on the snails.

\section{Methods}

Study system

We conducted our study in native coastal hind-dune vegetation at Sonoma Coast State Beaches adjacent to the University of California's Bodega Marine Reserve, Bodega Bay, California, USA ( $\left.38^{\circ} 19^{\prime} \mathrm{N}, 123^{\circ} 3^{\prime} \mathrm{W}\right)$. This site is characterized by highly seasonal rainfall, with $>90 \%$ of the annual precipitation falling between October and April. The dominant plants at our study site include three shrubs, false heather (Ericameria ericoides), silver bush lupine (Lupinus chamissonis), and California buckwheat (Eriogonum latifolium). Bush lupine (Lupinus arboreus) is also present but at considerably lower levels (see McNeil and Cushman 2005). A variety of other species are also found on the dunes, including the nonnative annual grass Vulpia bromoides and many native perennial forbs. The habitat, climate, and species of this area are described in detail in Barbour et al. (1973).

Numerous vertebrate and invertebrate herbivore species are common in this dune system. Especially abundant year-round vertebrate herbivores at our study site include black-tailed deer (Odocoileus hemionus columbianus) and black-tailed jackrabbits (Lepus californicus) (Warner and Cushman 2002). These two mammals feed on the shrubs, forbs, and grasses at the study site throughout the year. Four common invertebrate herbivores seasonally feed on the plants in this community. The introduced European garden snail (Helix aspersa) and the smaller, less common native shoulderband snail (Helminthoglypta arrosa) become active aboveground during the rainy season (roughly January through April). These snails avoid prolonged exposure to sunlight or dry conditions and are primarily active from late evening through early morning, except on rainy days. They live two to three years and aestivate during drier periods by attaching themselves to the undersides of woody structures above ground level (Van der Laan 1971; M. Huntzinger, unpublished data). Another common invertebrate herbivore in this habitat is the wooly bear caterpillar (Arctiidae: Platyprepia virginalis). Populations of this species fluctuate by several orders of magnitude among years (R. Karban, unpublished data). Young caterpillars hatch in early summer and feed in lupine litter until late in winter, when polyphagous later instars move into the plant canopy. The late-instar caterpillars are highly visible, feed voraciously on shrubs and forbs, and grow quickly during spring. They pupate, metamorphose into tiger 
moths, and reproduce in late spring (Karban and English-Loeb 1997). Only one species of grasshopper (Microtes occidentalis) is common at our sites. It is a habitat specialist, restricted to coastal dunes, from this site south to southern California (Strohecker et al. 1968). Nymphal and adult M. occidentalis can be found from May to October feeding on shrubs, forbs, and grasses.

\section{Herbivore-exclosure experiment}

We conducted our study using an herbivore-exclusion experiment established by one of us (J. H. Cushman) in May 1995 within a $210 \times 20 \mathrm{~m}$ section of dune trough. The experiment employs a randomized block design and consists of 20 plots arranged in five blocks of four. Each plot is $6 \times 6 \mathrm{~m}$ in size and neighboring plots within blocks are separated by $6 \mathrm{~m}$. The blocks are arranged in a linear sequence within a dune trough, with $20 \mathrm{~m}$ separating neighboring blocks. Each plot within a block was randomly assigned to receive one of the following manipulations: jackrabbits were excluded, deer were excluded, both jackrabbits and deer were excluded, or both herbivores were present (control). Jackrabbits have been excluded from plots using $60-\mathrm{cm}$-high woven-wire fencing, with the wire flaring out at ground level to prevent jackrabbits from burrowing underneath. These fences are sufficiently high to exclude jackrabbits, but are low enough to allow deer access (the jackrabbit fencing does not influence meadow voles and deer mice but probably does exclude the less abundant striped skunk; J. H. Cushman, personal observation). Deer have been excluded from plots with 2-m-high woven-wire fencing that extends to within $40 \mathrm{~cm}$ of the ground, thereby allowing access to jackrabbits and other small mammals. Control plots received metal posts at each of their corners but no fencing. Within each plot, there are nine $50 \times 50 \mathrm{~cm}$ permanently marked sampling quadrats laid out systematically in a grid.

\section{Influence of vertebrates on invertebrate abundance}

To determine whether jackrabbits or deer affected snail abundance at our study site, we first counted unoccupied snail shells in each plot in January 2003. Snail shells take several years to decompose in this habitat (M. Huntzinger, unpublished data), so shells found in 2003 indicated snails that died in situ in any of the previous two or three years (2000-2002). From February to May 2003 and January to May 2004, we determined the abundance of living snails within each plot between 06:00 and 09:00 hours, a total of five times in each year. We identified each snail to species and marked it with a black indelible pen (Sharpie) to avoid recounting. Total numbers of shells or snails were summed for each plot. Numbers of the native snail species were insufficient to analyze separately, so we combined them with the introduced snail species to meet the assumptions of parametric statistics.
As mentioned earlier, the jackrabbit fencing probably excluded other similarly sized mammals, such as striped skunks (Mephitis mephitis), which are present but uncommon at our site. Skunks are omnivores and at least $90 \%$ of their diet is comprised of animal material (Martin et al. 1951). We were concerned that snail predation by skunks could create the appearance of competitive reduction of snails by jackrabbits. To determine the importance of predation by skunks and other potential mammalian and avian predators, we conducted an experiment to assess disappearance rates of snails during February and March 2004. We placed marked snails in 45-cm-diameter round arenas located in each plot. The arenas consisted of rings of stiff plastic topped with copper tape to discourage snails from escaping. We placed each arena in low-growing vegetation to reduce escapes, and added cabbage leaves every two to three days to assure that food scarcity was not the cause of snail movements. We recorded disappearances from each arena over four-day intervals spanning 21 days. We assumed that disappearances from arenas were caused by predation. We believe we overestimated predation rates because we found that arenas were less than $100 \%$ effective at preventing snail movement. We also assumed that the 21 days of the experiment were representative of other times. To determine whether disappearance rates were higher in the plots that allowed access to jackrabbits, and hence also skunks and other predators, we conducted a test of association between persistence of 42 snails in each of the four fencing treatments in all five blocks (three-way $G$ test of independence; Sokal and Rohlf 1969). If predation was important, we expected snails to disappear more frequently from treatments that allowed access to skunks and other predators.

To determine whether jackrabbits or deer affected wooly bear caterpillar abundance, we visually censused caterpillars three times in March and April 2003 and twice in April 2004 and pooled counts from different sample dates. We counted third and fourth instars that feed on foliage above ground (first and second instars feed in the litter and are not readily visible). Abundances of caterpillars in 2004 were insufficient to analyze separately, so we combined them with those from 2003 for statistical analyses.

To determine whether jackrabbits or deer influenced the abundance of grasshoppers at our site, we surveyed grasshoppers on three dates between June and August 2003 and on two dates in July 2004. We determined the abundance of grasshoppers within the nine permanent quadrats within each plot. We pooled data from different dates within each year.

We evaluated our invertebrate data from the exclosure experiment using a three-way multivariate analysis of variance (MANOVA), with jackrabbit treatment (present or absent), deer treatment (present or absent), and block (1-5) as the grouping factors and Wilks' lambda as our test statistic. The six response variables 
for this MANOVA were snail shell abundance in 20002002, living snail abundance in 2003 and 2004, caterpillar abundance in 2003 and 2004 (combined), and grasshopper abundance in 2003 and 2004. When the MANOVA produced significant treatment effects, we proceeded with "protected" ANOVAs (sensu Scheiner 2001) on individual response variables. As discussed by Scheiner (2001), this approach is an effective method for dealing with potential correlations among multiple dependent variables.

\section{Influence of vertebrate herbivores on dune vegetation}

To assess the possible mechanisms by which jackrabbits and deer might influence invertebrate herbivores, we determined the effects of mammalian herbivores on dune vegetation after 11 years of experimental exclosure. To do so, we estimated the volume of four different vegetation groups in April 2006: grasses, forbs, and each of the two common shrubs, Ericameria ericoides and Lupinus spp. (L. chamissonis and L. arboreous). We also measured the mean percentage of grasses that were in flower. Our simple estimate of volume was calculated by multiplying the mean area covered with the mean height of each of the plant groups in six of the nine $50 \times 50 \mathrm{~cm}$ quadrats in each plot. As before, we analyzed our response variables using a three-way MANOVA, with jackrabbit treatment (present or absent), deer treatment (present or absent), and block (1-5) as the grouping factors. When the MANOVA produced significant treatment effects, we again proceeded with protected ANOVAs on individual response variables.

\section{Mechanisms for vertebrate effects on snails}

We established an additional experiment to address the possible mechanisms by which vertebrate herbivores affect snail abundance. Vertebrates could reduce the quality of the environment for snails in at least three possibly ways: (1) they may consume the highest quality food so that snails become food limited, (2) they may change the structure of the vegetation so that fewer woody structures are available for snails to use, and/or (3) they may alter the vegetation so that shade is less abundant. Our experiment to address these possibilities was conducted in the hind dunes immediately west of the long-term vertebrate exclosures. Our experiment consisted of $1 \times 1 \mathrm{~m}$ plots that were each assigned randomly to three treatments in a crossed fashion. The treatments consisted of supplemental food $(+,-)$, structure $(+,-)$, and shade $(+,-)$ with each combination of treatments replicated seven times. The corners of each plot were marked with wooden stakes and were located at least 1 $\mathrm{m}$ from other plots. No barriers to movement were placed around the plots and snails and other organisms could move freely among them. The experiment was conducted twice: from 23 February to 20 April 2005 and from 11 March to 16 April 2006.

For plots assigned to receive supplemental food, we placed one leaf of organically grown cabbage on the ground and replaced it every week of the experiment. Snails readily consumed the cabbage leaf and we found that some of the leaf was generally still present with a one-week replacement interval. For plots assigned to receive supplemental structure, we placed one dead lupine bush in the center of the plot. This bush provided a woody structure but had no leaves. For plots assigned to receive a moderate amount of supplemental shade, we attached a $0.5 \times 0.5 \mathrm{~m}$ shade cloth $(50 \%$ shade $)$ suspended $\sim 20-30 \mathrm{~cm}$ above the ground.

Into each of our plots, we placed one adult snail $(H$. aspersa) at the start of the experiment and other snails were removed to provide an equal initial density. We numbered all snails encountered during the experiment using black, indelible-ink pens, which allowed us to record their movements and determine recapture rates. We surveyed all plots for snails six times at weekly intervals in 2005 and four times in 2006. We evaluated data on cumulative abundance of snails per year per plot using a four-way ANOVA (JMP; SAS Institute 2003), with food $(+,-)$, structure $(+,-)$, shade $(+,-)$, and year $(2005,2006)$ as the grouping factors.

\section{RESUlts}

\section{Influence of vertebrates on invertebrate abundance}

Removal of jackrabbits and deer significantly affected the abundances of invertebrate herbivores in our coastal dune system (MANOVA overall Wilks' $\lambda, F_{24,33}=3.65$, $P=0.0004$; jackrabbit treatment: $F_{4,9}=10.52, P=0.002$; deer treatment: $\left.F_{4,9}=3.29, P=0.06\right)$. Since neither block $\left(F_{16,28}=1.90, P=0.07\right)$ nor the jackrabbit $\times$ deer interaction term $\left(F_{4,9}=1.63, P=0.25\right)$ were significant, we report only the main effects, although block and the interaction were included in all ANOVAs.

Jackrabbits reduced the number of snail shells deposited in plots prior to 2003 by $44 \%\left(F_{1,13}=9.47\right.$, $P=0.01)$ and reduced the abundance of living snails by $45 \%$ in $2003\left(F_{1,13}=5.45, P=0.04\right)$ and $75 \%$ in 2004 $\left(F_{1,13}=9.56, P=0.01\right.$; Fig. $\left.1 \mathrm{~A}\right)$. Although we lumped the two snail species to increase our statistical power, there were similar reductions for both species. In contrast, we were unable to detect a clear effect of deer on snail numbers. Deer reduced snail shells deposited in plots prior to 2003 by $32 \%\left(F_{1,13}=4.38, P=0.06\right)$, and we detected no significant reduction in the abundance of living snails by deer in 2003 and 2004 (2003, $F_{1,13}=1.30$, $P=0.28 ; 2004, F_{1,13}=2.72, P=0.13$; Fig. 1 B).

Our herbivore fencing manipulations did not have significant effects on the persistence of snails (Tables 1 and 2). In particular, there was no suggestion that plots that allowed access to jackrabbits and other mammals, such as skunks, had higher disappearance (predation) rates of snails (jackrabbits $\times$ persistence independence in Tables 1 and $2 ; P>0.50)$.

Jackrabbits and deer had significant but opposing effects on the abundance of wooly bear caterpillars. Jackrabbits reduced the abundance of wooly bear caterpillars in plots by $36 \%\left(F_{1,13}=16.96, P=0.001\right.$; 


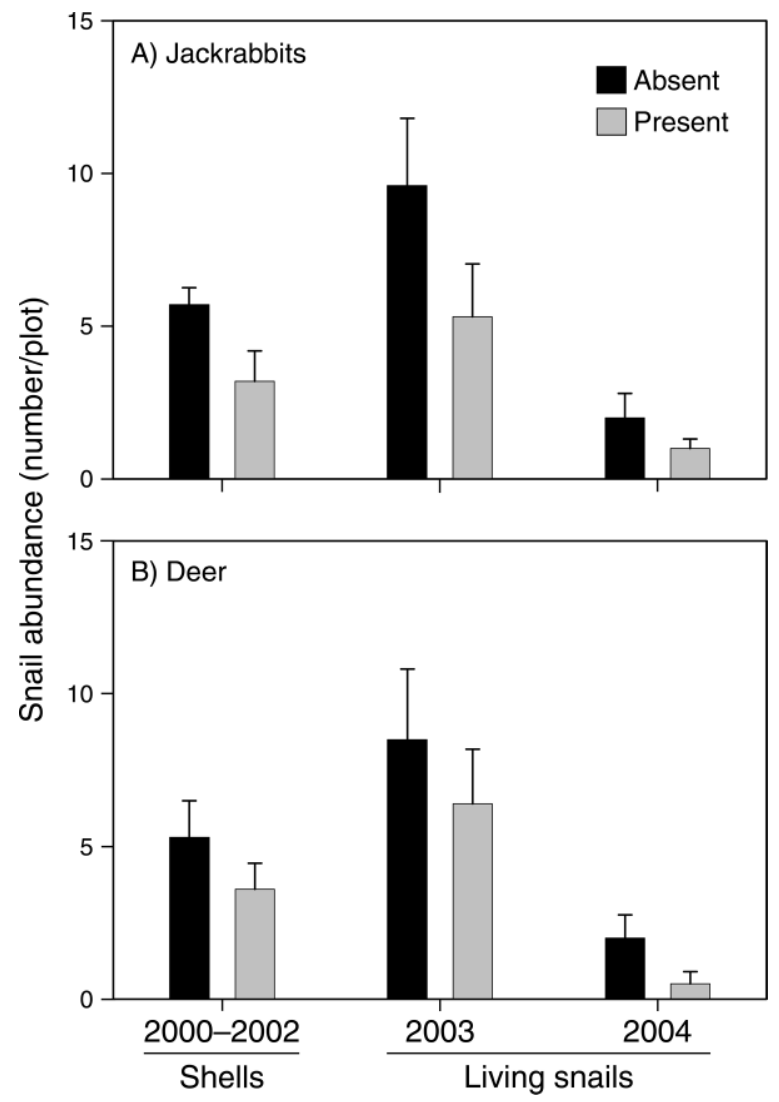

FIG. 1. Snail abundance as a function of the presence or absence of (A) jackrabbits and (B) deer. Data are means + SE; error bars in figures are based on all blocks, although including block in statistical analyses improved their power to detect treatment differences even where error bars overlap.

Fig. 2A). In contrast, deer increased the abundance of caterpillars in plots by $31 \%\left(F_{1,13}=6.35, P=0.03\right.$; Fig. 2B).

Grasshopper abundances were reduced by the presence of jackrabbits but not by the presence of deer. In plots with jackrabbits, grasshoppers were $62 \%$ less common than in plots without jackrabbits $\left(F_{1,13}=\right.$ 12.19, $P=0.004$; Fig. 3). The presence of deer increased

TABLE 1. Effects of jackrabbits and deer (herbivore fencing manipulations) on the persistence or disappearance of marked snails.

\begin{tabular}{|c|c|c|c|c|}
\hline \multicolumn{2}{|l|}{ Treatment } & \multicolumn{3}{|c|}{ No. marked snails } \\
\hline Jackrabbits & Deer & Persisted & Disappeared & Totals \\
\hline \multirow{3}{*}{ Present } & Present & 35 & 7 & 42 \\
\hline & Absent & 36 & 6 & 42 \\
\hline & Total & 71 & 13 & 84 \\
\hline \multirow[t]{3}{*}{ Absent } & Present & 33 & 8 & 41 \\
\hline & Absent & 34 & 8 & 42 \\
\hline & Total & 67 & 16 & 83 \\
\hline \multirow[t]{3}{*}{ Present and absent } & Present & 68 & 15 & 83 \\
\hline & Absent & 70 & 14 & 84 \\
\hline & Total & 138 & 29 & 167 \\
\hline
\end{tabular}

TABLE 2. MANOVA results of herbivore-fencing manipulations on persistence of snails.

\begin{tabular}{lcrc}
\hline \hline \multicolumn{1}{c}{ Hypothesis tested $\dagger$} & df & \multicolumn{1}{c}{$G$} & $P$ \\
\hline Jackrabbit $\times$ Deer independence & 1 & 0.004 & $>0.90$ \\
Jackrabbit $\times$ Persistence independence & 1 & 0.416 & $>0.50$ \\
$\begin{array}{l}\text { Deer } \times \text { Persistence independence } \\
\text { Jackrabbit } \times \text { Deer } \times \text { Persistence }\end{array}$ & 1 & -1.344 & $>0.20$ \\
$\quad \begin{array}{l}\text { interaction } \\
\text { Jackrabbit } \times \text { Deer } \times \text { Persistence }\end{array}$ & 1 & $\underline{1.446}$ & $>0.20$ \\
$\quad$ independence & 4 & 0.520 & $>0.90$ \\
\hline
\end{tabular}

Note: Underline indicates summation.

$\dagger$ "Independence" means these factors have independent effects; in this test we looked for a relationship between the presence of jackrabbits, the presence of deer, and/or the persistence of snails. A $P$ value $>0.05$ suggests the null hypothesis of no relationship cannot be ruled out.

grasshopper numbers, but not significantly $\left(F_{1,13}=1.35\right.$, $P=0.27)$.

\section{Influence of vertebrate herbivores on dune vegetation}

Jackrabbits and deer differed in their effects on the volume of grasses, forbs, Lupinus spp., and Ericameria ericoides as well as percentage of grasses in flower (MANOVA overall Wilks' $\lambda, F_{24,36}=2.53, P=0.006$; jackrabbit treatment, $F_{4,10}=10.64, P=0.0013$; deer treatment, $F_{4,10}=1.87, P=0.19$ ). Because we failed to detect a significant overall effect of deer on vegetation, results from further analyses focus solely on jackrabbits. The exclusion of jackrabbits significantly increased the volume of forbs by $44 \%\left(F_{1,13}=6.30, P=0.03\right.$; Fig. 4B $)$ and E. ericoides by $46 \%\left(F_{1,13}=6.52, P=0.024\right.$; Fig.

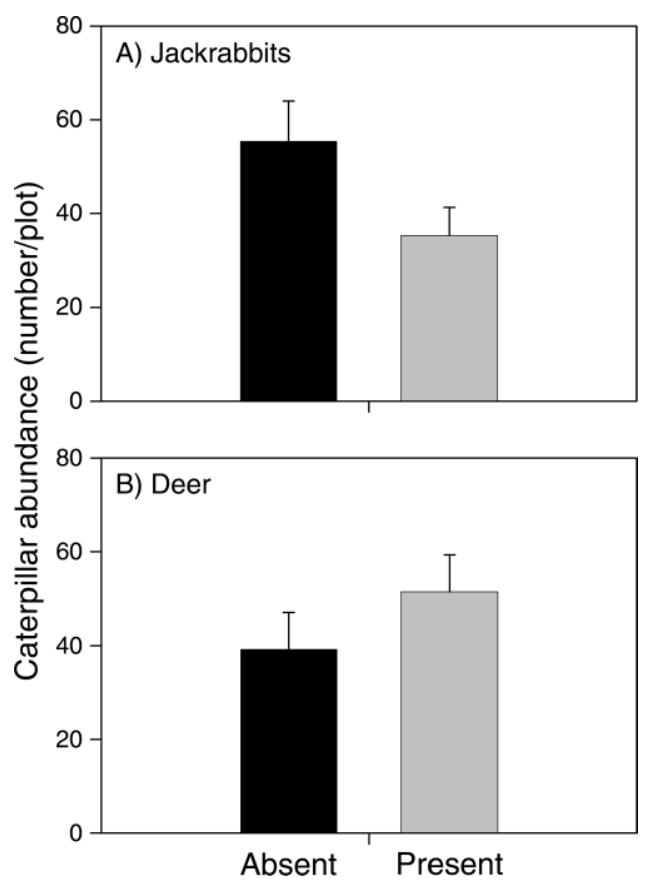

FIG. 2. Wooly bear caterpillar abundance as a function of the presence or absence of (A) jackrabbits and (B) deer. Data are means $+\mathrm{SE}$. 


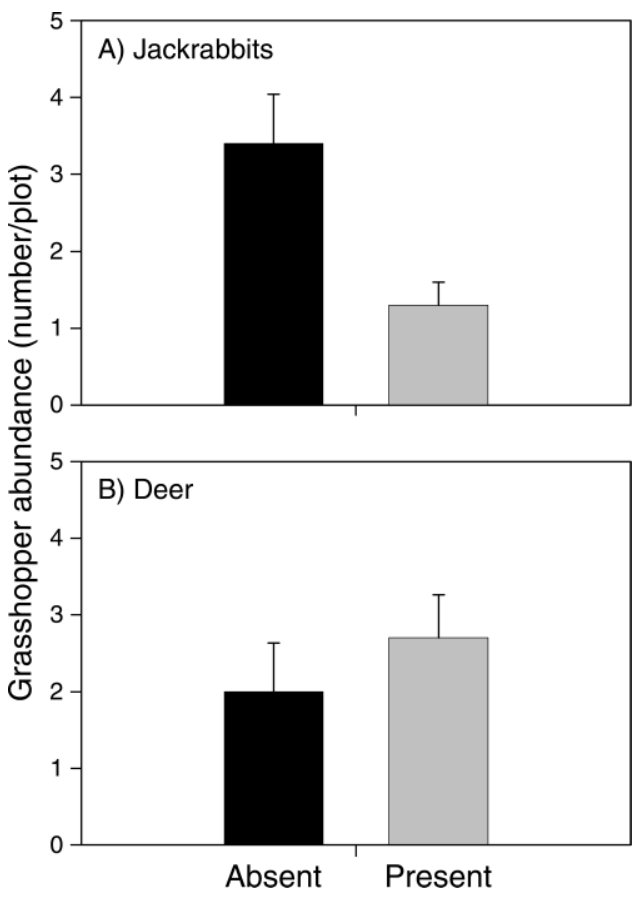

FIG. 3. Grasshopper abundance as a function of the presence or absence of (A) jackrabbits and (B) deer. Data are means + SE.

4C). Their exclusion also caused a $36 \%$ increase in the percentage of grasses that flowered (Fig. 4E). Exclusion of jackrabbits caused a $78 \%$ increase in volume of Lupinus spp., although this result was not significant at the 0.05 level $\left(F_{1,13}=4.06, P=0.065\right.$; Fig. $\left.4 \mathrm{D}\right)$. Exclusion of jackrabbits also increased the volume occupied by grasses, but not significantly $\left(F_{1,13}=2.18\right.$, $P=0.16$; Fig. 4A).

\section{Mechanisms for vertebrate effects on snails}

Vertebrate herbivores that affect the vegetation could reduce snail abundance by diminishing food available to snails, by diminishing physical structures used by snails during times of unfavorable conditions, or by reducing the amount of shade and humidity experienced by snails. Of these three possible mechanisms, we found support only for increases caused by supplemental shade $\left(F_{1,93}=\right.$ 10.55, $P=0.002$; Fig. 5). Neither supplemental food $\left(F_{1,93}=1.72, P=0.19\right)$ nor structure $\left(F_{1,93}=0.10, P=\right.$ $0.75)$ affected snail abundance. More snails were observed in our 2005 surveys than in $2006\left(F_{1,93}=\right.$ 9.73, $P=0.002$ ) although our result that shade was beneficial to snails was consistent in both years (shade $\times$ year interaction was not significant: $F_{1,88}=1.66, P=0$. 21) and no other interactions were significant.

\section{Discussion}

A growing number of studies are showing that herbivore species can negatively affect other distantly related herbivore taxa (see Introduction, above). Despite
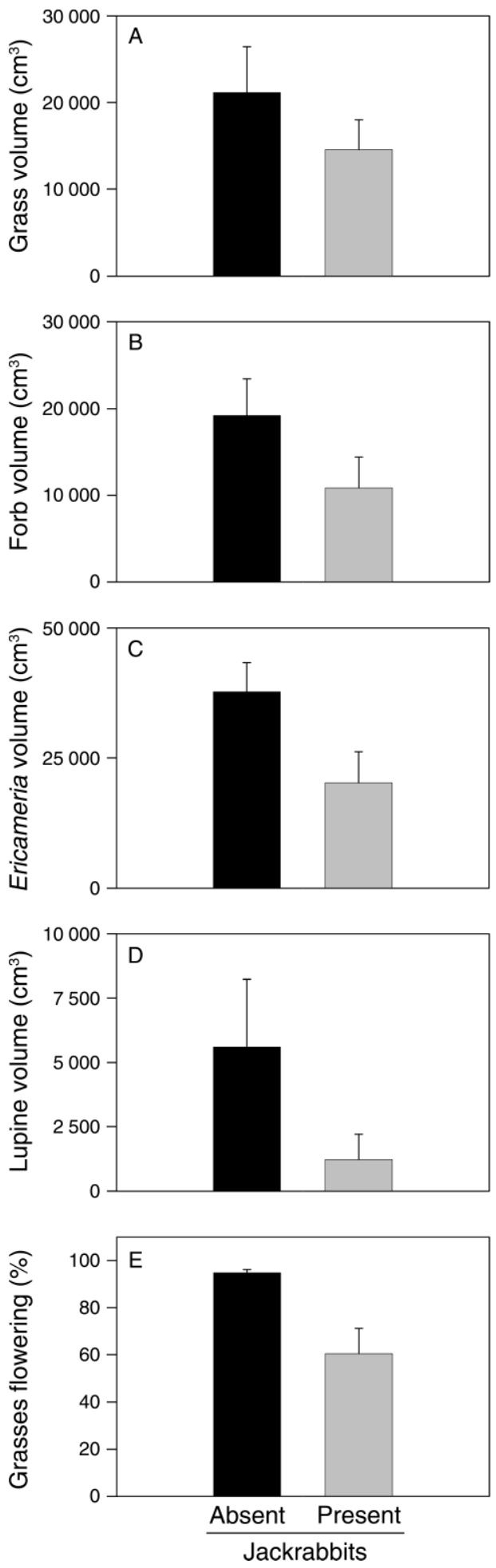

FIG. 4. Volume (in $\mathrm{cm}^{3}$ ) of (A) grasses, (B) forbs, (C) Ericameria ericoides, and (D) Lupinus spp. as a function of the presence or absence of jackrabbits. Also shown is (E) the percentage of grass plants that were flowering. Data are means $+\mathrm{SE}$. 

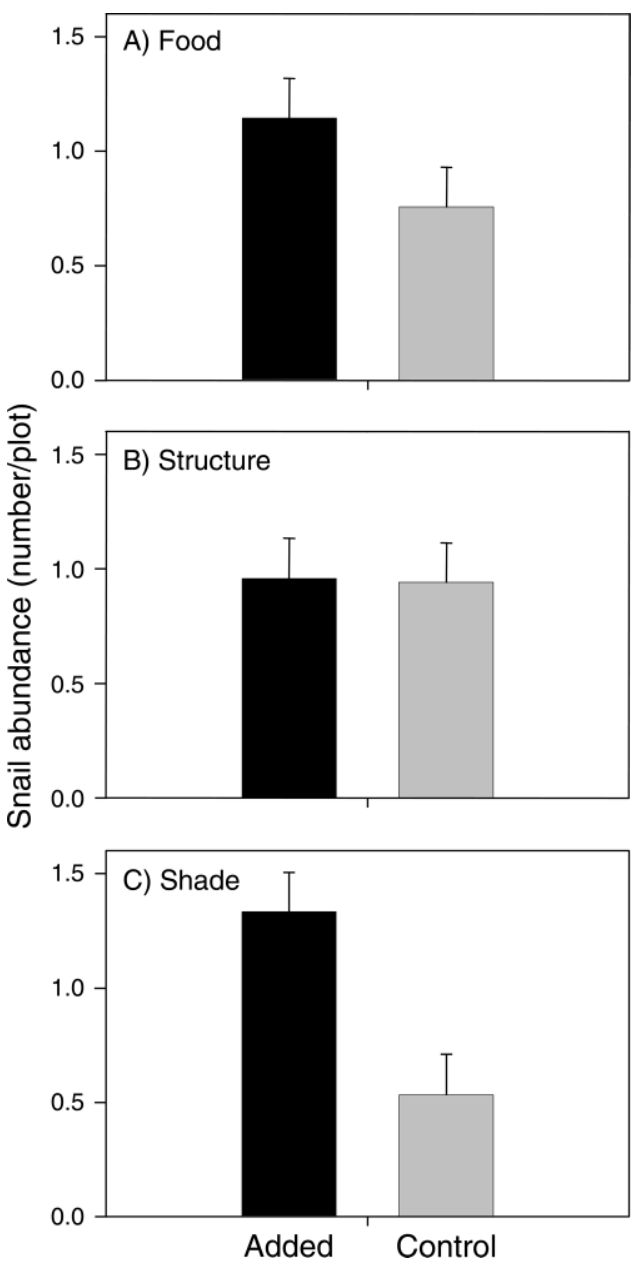

FIG. 5. Effects of supplemental food, structure, and shade on snail abundance (data are means $+\mathrm{SE}$ ); "added" indicates that the supplement was provided. We found no significant effect of food, no significant effect of structure, but a strong effect of added shade.

this list of interacting pairs or groups of herbivores from the literature, examples of competition in ecology textbooks rely primarily on closely related organisms (Stiling 2001, Begon et al. 2006, although see Ricklefs and Miller [1999] for an exception). Amensalism and other forms of negative interactions receive much less coverage than reciprocal competition. One reason for this disconnect is that it is very difficult to determine whether the examples of competition and amensalism cited above are truly common or whether the researchers specifically picked dramatic and unusual examples. Our study is the first that we know of to examine all of the potential effects that the most common large vertebrate herbivores have on the most common macroinvertebrate herbivores in a system. We had no a priori knowledge that any of these organisms would be likely to interact strongly. Rather, our study was motivated by a longterm, replicated, exclosure experiment that gave us the opportunity to examine possible effects of two wide- spread vertebrate herbivores on all of the common and apparent invertebrates at one site.

We found that in five of six cases, mammalian herbivores had strong significant effects on the invertebrate herbivores (Figs. 1-3). Four of these involved negative effects of jackrabbits and deer on snails, jackrabbits on wooly bear caterpillars, and jackrabbits on grasshoppers. We also found a positive effect of deer on caterpillars. Determining the causes responsible for the patterns in caterpillar and grasshopper abundance was beyond the scope of this study. In this same system, mammalian herbivores significantly depressed the abundance of leaf galls formed by the midge Dasineura lupinorum (Diptera: Cecidomyiidae) (Warner and Cushman 2002). This gall maker is a lupine specialist that rises to measurable densities in some years but was not abundant during our study. Other herbivore species were too uncommon for us to evaluate with this experimental design. In summary, the mammalian herbivores had large effects on the smaller invertebrate herbivores that commonly co-occur with them.

There are several mechanisms by which exclusion of mammalian herbivores could affect abundances of invertebrate herbivores, and here we have concentrated on effects on snails. First, many mammalian herbivores are actually omnivores that consume small invertebrates either intentionally or inadvertently when the invertebrate herbivores are present on the plant tissues that they ingest (Zamora and Gomez 1993). The fences in our study that exclude strict herbivores (such as jackrabbits) also exclude omnivores (such as skunks). Disappearance rates of snails were unaffected by treatments that allowed differential access by mammals (Tables 1 and 2) so that predation, either direct or inadvertent, is unlikely to cause greater numbers of snails (the only invertebrates examined in this portion of the study) in plots that excluded mammals.

A second potential mechanism to explain our exclosure results is that jackrabbits reduced the abundance of important food plants, and that these changes may have reduced abundances of the invertebrate herbivores. The volume occupied by forbs and shrubs was greater in plots that were protected from the mammalian herbivores, particularly jackrabbits (Fig. 4). These effects were not visible after the first few years but became more pronounced as the exclosure experiment continued (J. H. Cushman, personal observation). Thus, excluding herbivorous mammals may indirectly increase the abundance of invertebrate herbivores by increasing their food supplies or by changing the microenvironment.

A third potential mechanism to explain the exclosure results is that jackrabbits and deer may cause changes in plant quality as well as quantity. For example, at our dune study site, McNeil and Cushman (2005) found that deer herbivory significantly reduced carbon-to-nitrogen ratios of Lupinus chamissonis leaves, primarily due to increases in $\mathrm{N}$ content. Presumably because of these 
changes in leaf chemistry, deer herbivory significantly accelerated $\mathrm{N}$-mineralization rates underneath shrub canopies. In other studies, fairly subtle changes in the composition or quality of a few important plant species have been shown to have disproportionately large effects that reverberate throughout the ecosystem (e.g., Schmitz 2006).

We conducted shorter-term experiments to evaluate the roles that additional food, plant structure, and shade might play in affecting numbers of adult snails. Negative interactions are most commonly assumed to involve food limitation, although we found no evidence that adding cabbage leaves (a high-quality food that was consumed by snails in almost every case), increased the numbers of snails in our surveys (Fig. 5). By consuming leaves of adult shrubs and entire aboveground biomass of shrub seedlings, vertebrate herbivores reduced the volume of the two common shrubs at our site, Ericameria ericoides and Lupinus chamissonis. These shrubs may provide many services for snails including aestivation sites and shade structures. Snails aestivate and spend the day on the woody structures of these two plant species (M. Huntzinger, personal observation), so we hypothesized that additional woody structures could increase snail density. However, adding structure but no shade in the form of dead lupine bushes resulted in no additional snails in our surveys. In contrast, providing additional shade more than doubled snail numbers (Fig. 5). This evidence suggests that vertebrate herbivores can reduce snail numbers indirectly by acting as ecosystem engineers that change the physical environment experienced by snails (Jones et al. 1997). Interactions involving ecosystem engineering may be common when considering organisms of vastly different body sizes, as we are here. By virtue of their much larger size, the vertebrate herbivores are capable of affecting very profound changes to the environments of the much smaller, less mobile mollusks.

There are other indirect interactions between vertebrates and invertebrates that could be important. For example, vertebrate herbivores may have changed the abundance of invertebrate predators of the invertebrate herbivores through incidental predation while foraging. These hypothetical mechanisms are beyond the scope of our present study, although further experiments are underway to evaluate these multiple indirect effects.

In conclusion, we found strong effects of removal of vertebrate herbivores on the common invertebrate herbivores in our system. Competition is a pairwise interaction in which both participants negatively affect each other. It would be interesting to examine the effects of invertebrate herbivores on vertebrates, although these experiments are logistically difficult.

Competition involving shared resources between closely related taxa is both intuitive and has been commonly reported since at least Darwin's Origin of Species. Our results showing strong effects of vertebrates on invertebrates do not undermine the logic of Darwin's assertion that species in the same genus are likely to be more similar and therefore more competitive than distantly related species. However, although interactions between congeners may be stronger, co-existing congeners are far less abundant in most systems than coexisting distantly related organisms that share resources. Our results, along with those of a growing list of other studies, suggest that interactions between distantly related species are likely to be far more common than previously thought. Our results also highlight the importance of conditions and resources other than food as factors that can possibly limit populations of herbivores. Natural systems are inherently complex so we try to simplify them, by necessity. Potential interactions between distantly related herbivores, though less simple, should not be ignored, and mechanisms, both trophic and nontrophic, that underlie those interactions should be explored.

\section{ACKNOWLEDGMENTS}

We thank John Maron and Peter Connors for invaluable assistance in establishing the exclosures and Andy Sih and Truman Young for improving the manuscript. Our research has been generously supported by UC Intercampus Travel Grants, Jastro Shields grants to M. Huntzinger, and the NSF (DEB9981663 to J. H. Cushman and DEB-0639885 to R. Karban).

This paper is contribution number 2394, Bodega Marine Laboratory, University of California-Davis.

\section{Literature Cited}

Abrams, P., B. A. Menge, G. G. Mittelbach, D. Spiller, and P. Yodzis. 1995. The role of indirect effects in food webs. Pages 371-395 in G. A. Polis and K. O. Winemiller, editors. Food webs: integration of pattern and dynamics. Chapman and Hall, New York, New York, USA.

Bailey, J. K., and T. G. Whitham. 2002. Interactions among fire, aspen, and elk affect insect diversity: reversal of a community response. Ecology 83:1701-1712.

Bailey, J. K., and T. G. Whitham. 2003. Interactions among elk, aspen, galling sawflies and insectivorous birds. Oikos 101:127-134.

Barbour, M. G., R. B. Craig, F. R. Drydale, and M. T. Ghiselin. 1973. Coastal ecology: Bodega Head. University of California Press, Berkeley, California, USA.

Begon, M., J. L. Harper, and C. R. Townsend. 2006. Ecology: individuals, populations, and communities. Fourth edition. Blackwell Scientific, Oxford, UK.

Brown, J. H., and D. W. Davidson. 1977. Competition between seed eating rodents and ants in desert ecosystems. Science 196:880-882.

Connell, J. H. 1983. On the prevalence and relative importance of interspecific competition: evidence from field experiments. American Naturalist 122:661-696.

Danell, K., and K. Huss-Danell. 1985. Feeding by insects and hares on birches earlier affected by moose browsing. Oikos 44:75-81.

Darwin, C. 1859. On the origin of species. Signet Classics, Penguin Group, New York, New York, USA.

Denno, R. F., M. S. McClure, and J. R. Ott. 1995. Interspecific interactions in phytophagous insects: competition reexamined and resurrected. Annual Review of Entomology 40:297331.

Diamond, J. M. 1987. Competition among different taxa. Nature 326:241.

Galindo, C. 1986. Do desert rodent populations increase when ants are removed? Ecology 67:1422-1423. 
Gomez, J. M., and A. Gonzalez-Megias. 2002. Asymmetrical interactions between ungulates and phytophagous insects: being different matters. Ecology 83:203-211.

Gurevitch, J., L. L. Morrow, A. Wallace, and J. S. Walsh. 1992. A meta-analysis of competition in field experiments. American Naturalist 140:539-572.

Holt, R. D., and J. H. Lawton. 1994. The ecological consequences of shared natural enemies. Annual Review of Ecology and Systematics 25:495-520.

Jones, C. G., J. H. Lawton, and M. Shachak. 1997. Positive and negative effects of organisms as physical ecosystem engineers. Ecology 78:1946-1957.

Karban, R., and I. T. Baldwin. 1997. Induced responses to herbivory. University of Chicago Press, Chicago, Illinois, USA.

Karban, R., and G. English-Loeb. 1997. Tachinid parasitoids affect host plant choice by caterpillars to increase caterpillar survival. Ecology 78:603-611.

Martin, A. C., H. S. Zim, and A. L. Nelson. 1951. American wildlife and plants: a guide to wildlife food habits. Dover, New York, New York, USA.

McCauley, D. J., F. Keesing, T. P. Young, B. F. Allen, and R. M. Pringle. 2006. Indirect effects of large herbivores on snakes in an African savanna. Ecology 87:2657-2663.

McNeil, S. G., and J. H. Cushman. 2005. Indirect effects of deer herbivory on local nitrogen availability in a coastal dune ecosystem. Oikos 110:124-132.

Menge, B. A. 1997. Detection of direct versus indirect effects: were experiments long enough? American Naturalist 149: 801-823.

Mokany, A., and R. Shine. 2003. Competition between tadpoles and mosquito larvae. Oecologia 135:615-620.

Morin, P. J., S. P. Lawler, and E. A. Johnson. 1988. Competiton between aquatic insects and vertebrates: interaction strength and higher order interactions. Ecology 69: 1401-1409.

Ohgushi, T. 2005. Indirect interaction webs: herbivore-induced effects through trait change in plants. Annual Review of Ecology Evolution and Systematics 36:81-105.

Olofsson, J., and J. Strengbom. 2000. Response of galling invertebrates on Salix lanata to reindeer herbivory. Oikos 91: 493-498.
Pringle, R. M., T. P. Young, D. I. Rubenstein, and D. J. McCauley. 2007. Herbivore-initiated interaction cascades and their modulation by productivity in an African savanna. Proceedings of the National Academy of Sciences (USA) 104: 193-197.

Ricklefs, R. E., and G. Miller. 1999. Ecology. Fourth edition. W. H. Freeman, New York, New York, USA.

SAS Institute. 2003. JMP, version 5.0.1. SAS Institute, Cary, North Carolina, USA.

Scheiner, S. M. 2001. Manova: multiple response variables and multispecies interactions. Pages 94-112 in S. M. Scheiner and J. Gurevitch, editors. Design and analysis of ecological experiments. Second edition. Oxford University Press, Oxford, UK.

Schmitz, O. 2006. Predators have large effects on ecosystem properties by changing plant diversity, not plant biomass. Ecology 87:1432-1437.

Schoener, T. W. 1983. Field experiments on interspecific competition. American Naturalist 122:240-285.

Shimazaki, A., and T. Miyashita. 2002. Deer browsing reduces leaf damage by herbivorous insects through an induced response of the host plant. Ecological Research 17:527-533.

Sokal, R. R., and F. J. Rohlf. 1969. Biometry. W. H. Freeman, San Francisco, California, USA.

Stiling, P. 2001. Ecology: theories and applications. Fourth edition. Prentice-Hall, Upper Saddle River, New Jersey, USA.

Strauss, S. Y. 1991. Indirect effects in community ecology: their definition, study, and importance. Trends in Ecology and Evolution 6:206-210.

Strohecker, H. F., W. W. Middlekauff, and D. C. Rentz. 1968. The grasshoppers of California. Bulletin of the California Insect Survey 10:1-177.

Van der Laan, K. L. 1971. The population ecology of the terrestrial snail Helminthoglypta arrosa (Pulmonata: Helicidae). Dissertation. University of California, Berkeley, California, USA.

Warner, P. J., and J. H. Cushman. 2002. Influence of herbivores on a perennial plant: variation with life history stage and herbivore species. Oecologia 132:77-85.

Zamora, R., and J. M. Gomez. 1993. Vertebrate herbivores as predators of insect herbivores: an asymmetrical interaction mediated by size differences. Oikos 66:223-228. 